\title{
EVALUASI KINERJA KARYAWAN LEVEL PELAKSANA SATUAN PENGAMANAN PADA PERGURUAN TINGGI MENGGUNAKAN METODE SIMPLE ADDITIVE WEIGHTING
}

\author{
Aries Setiawan 1 , Adi Prihandono ${ }^{2}$ \\ ${ }^{1}$ Fakultas IImu Komputer, Universitas Dian Nuswantoro \\ Semarang, Indonesia, email : arissetya.005@gmail.com \\ ${ }^{2}$ Fakultas Ilmu Komputer, Universitas Dian Nuswantoro \\ Semarang, Indonesia, email : adimsssemarang@gmail.com
}

\section{ARTICLE INFO}

Article history:

Received : 28 June 2019

Received in revised form : 16 July 2019

Accepted : 25 July 2019

Available online : 31 July 2019

\begin{abstract}
Higher education has several elements of human resources; one of these elements is at the implementing level, namely the security unit or security guard. In self-reliant activities in work environment, this element functions as industrial security or security in the university environment. It is necessary to have a performance evaluation for the security unit that is useful to measure the success of certain targets of an agency; evaluation includes the self-value of each security unit including the variables of knowledge, skills, behavior, work results, and care to you. The method used for performance evaluation the security unit is Simple Additive Weighting. Based on the results of the test it was found that the alternative a 7 occupies the highest rank with a value of 80.33 with details of the value of 4 as many as 6 aspects (c3, c10, c16, c19, c24), value 3 as many as 15 aspects (c2, c4, c5, c7, c8, c9, c11, $c 12, c 14, c 15, c 17, c 18, c 20, c 23)$ and the value of 2 in 3 aspects $(c 1, c 6, c 13)$ exceeds alternative a20 with a number of values 4 more than a7, this is influenced by the weight of each aspect.
\end{abstract}

Keywords: Evaluation, Performance, Security unit, Simple Additive Weighting

\section{Pendahuluan}

Perguruan tinggi memiliki beberapa elemen sumber daya manusia, salah satu elemen tersebut terdapat pada level pelaksana yaitu satuan pengamanan atau satpam. Dalam aktivitas yang bersifat swakarsa di wilayah lingkungan kerjanya maka elemen ini berfungsi sebagai industrial security atau pengamanan perusahaan [1].

Terkait dengan lingkungan perguruan tinggi, kinerja satuan pengamanan meliputi variabel pengetahuan, ketrampilan, perilaku, hasil kerja, dan care to you. Semua aspek yang ada berhubungan dengan pelayanan terhadap elemen perguruan tinggi lainnya seperti mahasiswa,

Received June 28, 2019; Revised July 07, 2019; Accepted July 25, 2019 
dosen dan bagian pelayanan lainnya sampai dengan pihak luar yang berkepentingan terhadap elemen perguruan tinggi.

Harapan untuk senantiasa tercipta rasa aman dan terlindunginya lingkungan, aset perguruan tinggi maupun segenap elemen sumber daya manusia di dalamnya merupakan fungsi dari satuan pengamanan yang harus dipenuhi agar upaya yang merugikan perguruan tinggi dapat diantisipasi sesuai tugas pokok fungsi yang ditentukan oleh pimpinan satuan pengamanan [2].

Evaluasi kinerja berguna untuk mengukur keberhasilan target tertentu dari sebuah instansi, evaluasi mencakup pada nilai diri setiap satuan pengamanan. Hasil evaluasi selanjutnya dapat dijadikan langkah pengambilan kebijakan dari level pimpinan [3].

Pada penilaian sebelumnya, hasil nilai diperoleh dari penjumlahan setiap nilai aspek untuk kemudian di bagi dengan jumlah keseluruhan aspek penilaian. Semua aspek memiliki bobot yang sama.

Evaluasi kinerja satuan pengamanan dalam penelitian ini menggunakan metode Simple Additive Weighting. Menurut Hayatun Nufus (2016), proses penilaian metode ini didasarkan pada aspek dan bobot tertentu sehingga menghasilkan perolehan hasil yang signifikan dibanding penilaian kinerja secara manual sebuah instansi [4].

\section{Metode Penelitian}

2.1Pengumpulan Data

Teknik pengumpulan data dilakukan melalui studi pustaka, wawancara dan kuesioner. Wawancara dengan kepala sub bagian keamanan tentang aspek-aspek yang digunakan serta model penilaian yang dilakukan selama ini, yaitu dengan dengan cara pencarian rerata keseluruhan nilai aspek. Dari penilaian sebelumnya kemudian perlu dikembangkan dengan metode yang baru, untuk memudahkan perolehan data dibuat kuesioner penilaian mengenai kinerja setiap satuan pengamanan (alternatif) yang berisi 24 aspek yang setiap aspek berisi skor dengan skala peringkat nilai 1 (tidak memenuhi), 2 (perlu perbaikan), 3 (cukup memenuhi) dan 4 (memenuhi syarat).

\subsection{Metode Simple Additive Weighting}

Metode ini menggunakan konsep dengan melakukan penjumlahan hasil perkalian dengan bobot dari setiap varibel penilaian [3]. Pada proses perhitungan didalamnya dilakukan normalisasi pada matriks keputusan (X) dalam skala yang selanjutnya dapat dibandingkan dengan semua kelompok alternatif yang ada. Persamaan-persamaan yang dipakai dalam metode Simple Additive Weighting adalah sebagai berikut [5].

$R i j=\left\{\begin{array}{l}\frac{X i j}{M A X i x i j} \\ \frac{\operatorname{MIN} i x i j}{X i j}\end{array}\right.$

Keterangan :

MAX $i . x i j=$ nilai maksimal pada tiap baris kolom

MIN $i . x i j=$ nilai minimal dari tiap baris kolom

$\mathrm{X} i j=$ nilai baris kolom

$\mathrm{R} i j=$ nilai hasil normalisasi dari setiap alternatif (Ai) pada aspek (C) 
Preferensi hasil setiap alternatif $(\mathrm{V})$ :

$\mathrm{V}=\sum_{j=1}^{n} W j . R i j$

keterangan :

$\mathrm{W}=$ Bobot setiap aspek

$\mathrm{R} i j=$ nilai hasil normalisasi dari setiap alternatif $(\mathrm{A} i)$ pada aspek $(\mathrm{C})$

Nilai $\mathrm{V}$ diperoleh dari keseluruhan jumlah perkalian anatar matriks ternormalisasi dengan

bobot tiap aspek

\section{Hasil dan Pembahasan}

\subsection{Penetapan Karakter Penilaian}

Tabel 1. Karakter Penilaian

\begin{tabular}{ll}
\hline Karakter & Penilaian \\
\hline Memenuhi persyaratan & 4 \\
Cukup memenuhi persyaratan & 3 \\
Perlu perbaikan & 2 \\
Tidak memenuhi persyaratan & 1 \\
\hline
\end{tabular}

Penilaian dengan nilai angka 1 sampai 4, nilai diberikan oleh kepala sub bagian keamanan sesuai dengan karakter masing-masing alternatif atau satuan pengamanan.

\subsection{Penerapan Metode Simple Additive Weighting}

Berikut langkah-langkah perhitungan kinerja satuan pengamanan dengan metode Simple Additive Weighting:

A. Identifikasi aspek penilaian (c)

Tabel 2. Daftar aspek penilaian

\begin{tabular}{|c|c|c|c|}
\hline Variabel & $\begin{array}{l}\text { Kode } \\
\text { Aspek }\end{array}$ & Aspek & Bobo \\
\hline \multirow[t]{3}{*}{ Pengetahuan } & $\mathrm{c} 1$ & $\begin{array}{l}\text { Memahami peraturan baris berbaris dan } \\
\text { penghomatan militer }\end{array}$ & 2 \\
\hline & $\mathrm{c} 2$ & $\begin{array}{l}\text { Memahami perlengkapan perorangan dan } \\
\text { perlengkapan kerja satuan pengamanan }\end{array}$ & 4 \\
\hline & $\mathrm{c} 3$ & $\begin{array}{l}\text { Memahami SOP yang berlaku di perguruan } \\
\text { tinggi }\end{array}$ & 6 \\
\hline \multirow[t]{5}{*}{ Ketrampilan } & $\mathrm{c} 4$ & $\begin{array}{l}\text { Melaksanakan persiapan untuk menjalankan } \\
\text { tugas sebagai petugas sekuriti }\end{array}$ & 4 \\
\hline & $\mathrm{c} 5$ & $\begin{array}{l}\text { Melakukan baris-berbaris dan penghormatan } \\
\text { militer }\end{array}$ & 2 \\
\hline & c6 & Melakukan beladiri & 4 \\
\hline & c7 & Melakukan pencatatan dan pelaporan & 5 \\
\hline & $\mathrm{c} 8$ & Berkomunikasi lewat telpon & 4 \\
\hline
\end{tabular}

TRANSFORMATIKA Vol. 17, No. 1, July 2019: $26-33$ 


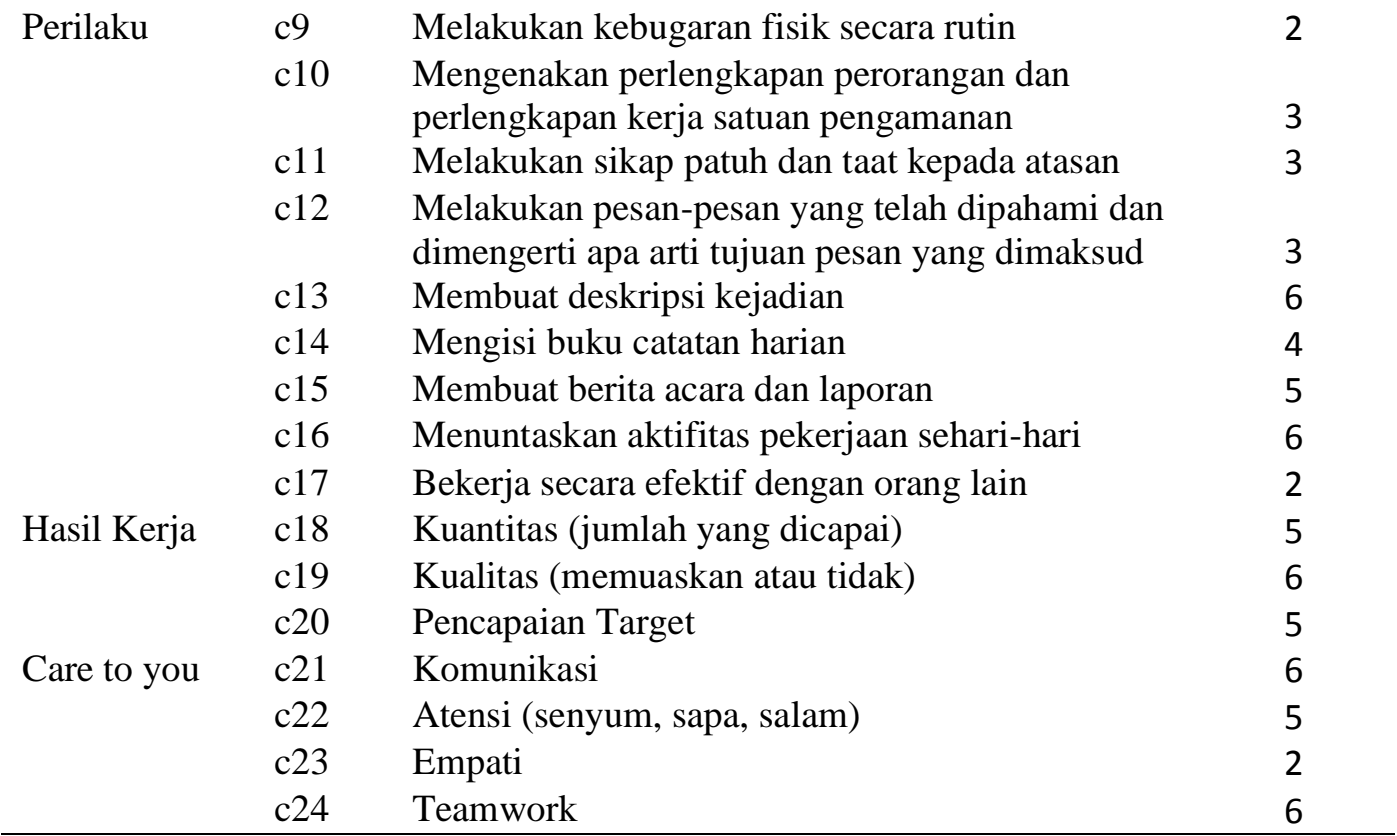

Bobot pada setiap aspek, nilainya sangat bervariatif, sesuai dengan tingkat kepentingan pihak pengambil keputusan. Bobot berbeda dengan nilai alternatif, bobot cenderung berupa nilai mengenai seberapa tingkat pengaruhnya aspek terhadap hasil penilaian setiap aspek.

B. Pengelompokan aspek ke dalam benefit dan cost

Tabel 3. Pengelompokan aspek

\begin{tabular}{|c|c|}
\hline $\begin{array}{l}\text { Jenis } \\
\text { aspek }\end{array}$ & Aspek \\
\hline benefit & $\begin{array}{l}\mathrm{c} 1, \mathrm{c} 2, \mathrm{c} 3, \mathrm{c} 4, \mathrm{c} 5, \mathrm{c} 6, \mathrm{c} 7, \mathrm{c} 8, \mathrm{c} 9, \mathrm{c} 10, \mathrm{c} 11, \mathrm{c} 12, \mathrm{c} 13, \mathrm{c} 14, \mathrm{c} 15, \mathrm{c} 16, \mathrm{c} 17, \mathrm{c} 18, \mathrm{c} 19, \mathrm{c} 20, \mathrm{c} 21, \mathrm{c} 22, \mathrm{c} 23 \\
\mathrm{,c} 24\end{array}$ \\
\hline cost & - \\
\hline
\end{tabular}

Benefit lebih difungsikan untuk aspek yang sifatnya menunjang pada hasil sedangkan cost lebih berupa akibat dari adanya benefit. Pada penelitian ini semua aspek yang berjumlah 24 aspek lebih difokuskan pada benefit.

C. Penilaian Alternatif (A)

Merupakan nilai masing-masing alternatif pada setiap aspek yang ada.

Tabel 4. Penilaian Alternatif

\begin{tabular}{|c|c|c|c|c|c|c|c|c|c|c|c|c|c|c|c|c|c|c|c|c|c|c|c|c|}
\hline$\stackrel{\Xi}{\frac{D}{2}}$ & $\bar{u}$ & ช & $\hat{\gamma}$ & オ & 3 & ర & $\hat{0}$ & $\stackrel{\infty}{0}$ & jे & $\frac{}{u}$ & $\bar{v}$ & $\frac{\sim}{0}$ & $\frac{m}{u}$ & $\frac{\Delta}{u}$ & $\frac{n}{u}$ & $\frac{b}{0}$ & J & $\stackrel{\infty}{u}$ & $\frac{\partial}{0}$ & ণิ & $\bar{\nu}$ & ปิ & ชิ & $\underset{v}{J}$ \\
\hline a1 & 3 & 4 & 4 & 4 & 2 & 2 & 3 & 3 & 2 & 3 & 3 & 3 & 3 & 2 & 2 & 3 & 3 & 3 & 3 & 3 & 3 & 3 & 2 & 3 \\
\hline a2 & 3 & 3 & 4 & 3 & 2 & 2 & 3 & 3 & 2 & 3 & 2 & 2 & 3 & 2 & 2 & 3 & 3 & 3 & 3 & 3 & 3 & 3 & 2 & 3 \\
\hline a3 & 3 & 3 & 4 & 3 & 2 & 2 & 3 & 3 & 2 & 2 & 3 & 3 & 3 & 4 & 2 & 3 & 3 & 3 & 2 & 3 & 2 & 3 & 3 & 3 \\
\hline a4 & 3 & 3 & 3 & 3 & 2 & 2 & 3 & 3 & 2 & 3 & 3 & 3 & 4 & 3 & 2 & 3 & 4 & 3 & 3 & 3 & 3 & 4 & 3 & 3 \\
\hline
\end{tabular}




\begin{tabular}{lllllllllllllllllllllllll}
$\mathrm{a} 5$ & 3 & 3 & 3 & 3 & 2 & 2 & 3 & 3 & 2 & 3 & 4 & 3 & 3 & 3 & 2 & 2 & 3 & 3 & 4 & 2 & 1 & 2 & 3 & 3 \\
$\mathrm{a} 6$ & 2 & 3 & 4 & 4 & 2 & 2 & 4 & 3 & 2 & 3 & 3 & 3 & 3 & 4 & 3 & 3 & 3 & 2 & 3 & 3 & 3 & 3 & 4 & 3 \\
$\mathrm{a} 7$ & 2 & 3 & 4 & 3 & 3 & 2 & 3 & 3 & 3 & 4 & 3 & 3 & 2 & 3 & 3 & 4 & 3 & 3 & 4 & 3 & 3 & 3 & 3 & 4 \\
$\mathrm{a} 8$ & 3 & 4 & 4 & 3 & 3 & 2 & 3 & 3 & 3 & 2 & 3 & 3 & 3 & 3 & 4 & 3 & 3 & 3 & 3 & 3 & 3 & 3 & 3 & 3 \\
$\mathrm{a} 9$ & 3 & 3 & 2 & 3 & 2 & 2 & 3 & 2 & 3 & 3 & 3 & 3 & 3 & 3 & 3 & 3 & 3 & 3 & 3 & 3 & 3 & 3 & 3 & 3 \\
$\mathrm{a} 10$ & 2 & 3 & 3 & 4 & 2 & 2 & 3 & 3 & 3 & 3 & 3 & 3 & 4 & 3 & 3 & 3 & 3 & 3 & 3 & 3 & 1 & 3 & 3 & 3 \\
$\mathrm{a} 11$ & 2 & 3 & 3 & 3 & 3 & 2 & 3 & 3 & 3 & 3 & 3 & 3 & 2 & 3 & 3 & 4 & 3 & 3 & 3 & 3 & 3 & 3 & 3 & 3 \\
$\mathrm{a} 12$ & 3 & 3 & 3 & 3 & 3 & 2 & 2 & 4 & 3 & 4 & 3 & 2 & 2 & 3 & 3 & 3 & 4 & 3 & 3 & 3 & 3 & 4 & 4 & 4 \\
$\mathrm{a} 13$ & 2 & 3 & 4 & 3 & 3 & 2 & 2 & 3 & 3 & 2 & 3 & 2 & 3 & 3 & 4 & 3 & 3 & 2 & 3 & 1 & 4 & 3 & 3 & 3 \\
$\mathrm{a} 14$ & 2 & 3 & 4 & 3 & 3 & 2 & 2 & 3 & 3 & 1 & 3 & 2 & 3 & 4 & 3 & 4 & 3 & 3 & 2 & 3 & 3 & 3 & 3 & 3 \\
$\mathrm{a} 15$ & 2 & 3 & 4 & 4 & 3 & 2 & 3 & 3 & 3 & 3 & 3 & 4 & 3 & 2 & 3 & 3 & 3 & 3 & 4 & 3 & 3 & 2 & 4 & 3 \\
$\mathrm{a} 16$ & 2 & 3 & 3 & 3 & 2 & 3 & 3 & 4 & 3 & 3 & 3 & 2 & 4 & 2 & 3 & 3 & 3 & 1 & 3 & 3 & 3 & 2 & 3 & 3 \\
$\mathrm{a} 17$ & 2 & 3 & 4 & 3 & 2 & 2 & 4 & 3 & 3 & 4 & 3 & 2 & 2 & 3 & 3 & 3 & 4 & 3 & 3 & 3 & 4 & 1 & 3 & 4 \\
$\mathrm{a} 18$ & 2 & 2 & 4 & 2 & 2 & 2 & 3 & 4 & 2 & 2 & 4 & 3 & 3 & 3 & 3 & 3 & 3 & 1 & 3 & 3 & 3 & 3 & 4 & 3 \\
$\mathrm{a} 19$ & 3 & 3 & 4 & 2 & 2 & 2 & 3 & 2 & 2 & 3 & 3 & 2 & 2 & 3 & 3 & 3 & 3 & 3 & 3 & 3 & 3 & 4 & 3 & 2 \\
$\mathrm{a} 20$ & 3 & 3 & 3 & 2 & 4 & 4 & 4 & 4 & 4 & 4 & 4 & 3 & 3 & 3 & 4 & 3 & 1 & 3 & 3 & 4 & 2 & 1 & 3 & 3 \\
$\mathrm{a} 21$ & 3 & 3 & 4 & 2 & 3 & 3 & 2 & 3 & 2 & 2 & 3 & 3 & 4 & 3 & 3 & 4 & 2 & 3 & 3 & 3 & 3 & 4 & 3 & 4 \\
$\mathrm{a} 22$ & 3 & 3 & 2 & 3 & 3 & 3 & 2 & 4 & 2 & 3 & 3 & 3 & 2 & 3 & 2 & 3 & 2 & 3 & 3 & 2 & 3 & 3 & 3 & 3 \\
$\mathrm{a} 23$ & 3 & 3 & 3 & 3 & 2 & 2 & 3 & 3 & 2 & 3 & 3 & 3 & 2 & 3 & 2 & 3 & 3 & 3 & 3 & 3 & 3 & 3 & 3 & 2 \\
\hline
\end{tabular}

Nilai yang dimiliki oleh setiap alternatif sangat bervariatif, nilai 4 pada setiap aspeknya merupakan nilai tertinggi untuk aspek tersebut. Jika terdapat beberapa alternatif memiliki nilai 4 dengan jumlah banyak yang sama namun pada aspek yang berbeda, belum tentu memiliki hasil akhir penilaian yang sama imbang, karena hasil akhir juga dipengaruhi oleh kapasitas bobot masing-masing aspek.

\section{Proses normalisasi (matrix X)}

Proses normalisasi keputusan $(\mathrm{R})$ dengan cara membandingkan setiap alternatif terhadap nilai terbesar dari dari keseluruhan alternatif yang ada. Dengan rumus

$$
R=\frac{\text { Nilai dari setiap Alternatif }}{M A X(\text { Nilai per aspek keseluruhan alternatif })}
$$

Sehingga dihasilkan tabel matrik sebagai berikut :

Tabel 5. Nilai Normalisasi (R) dari semua aspek

$$
\begin{aligned}
& \text { 苞 } \\
& \text { ప }
\end{aligned}
$$

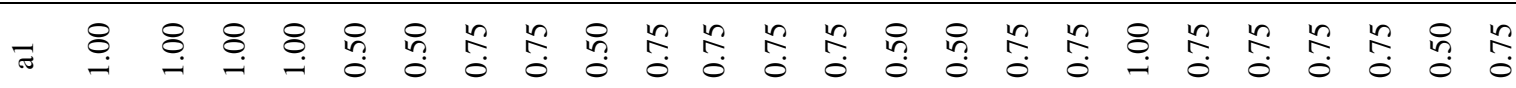

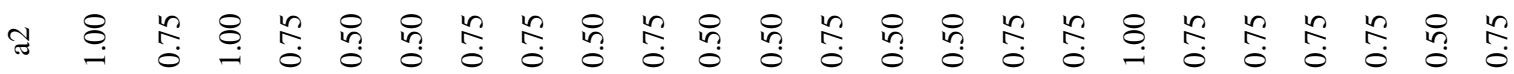

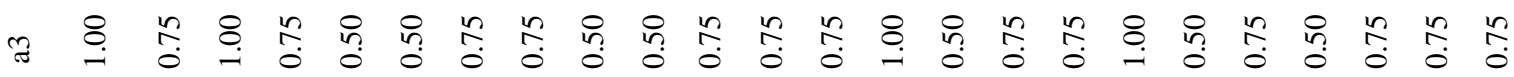

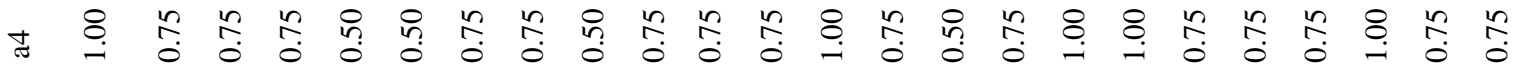

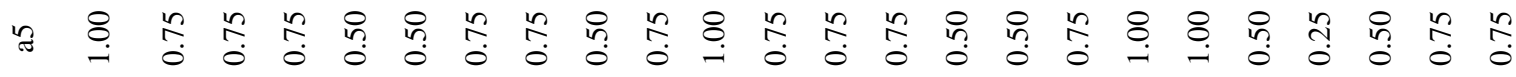

TRANSFORMATIKA Vol. 17, No. 1, July 2019: $26-33$ 


$$
\begin{aligned}
& \text { - }
\end{aligned}
$$

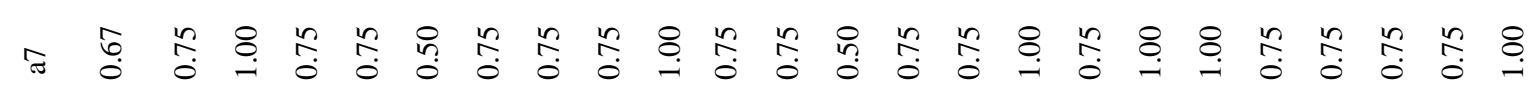

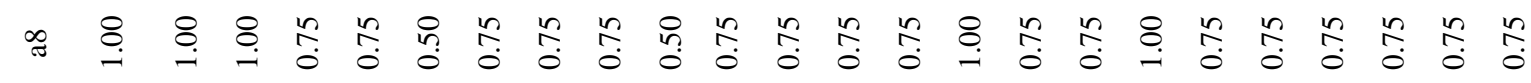

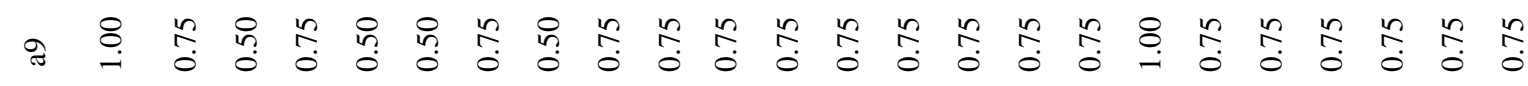

$$
\begin{aligned}
& \text { 은 }
\end{aligned}
$$

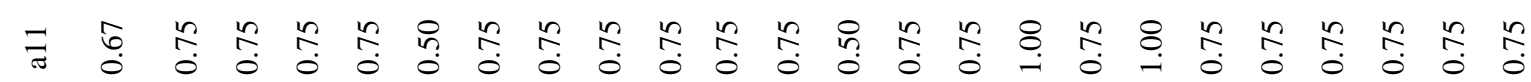

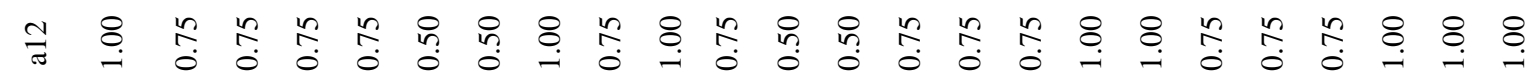

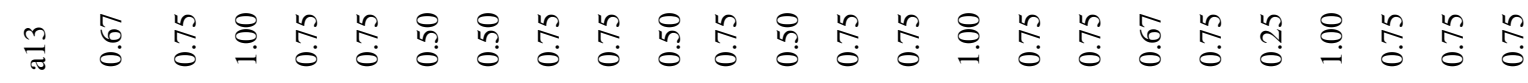

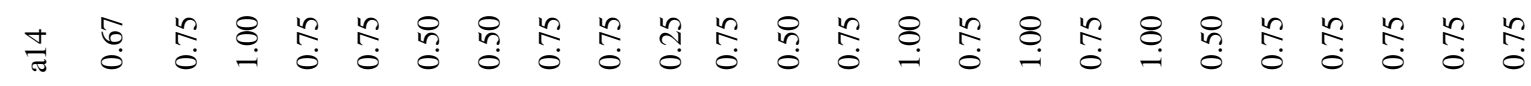

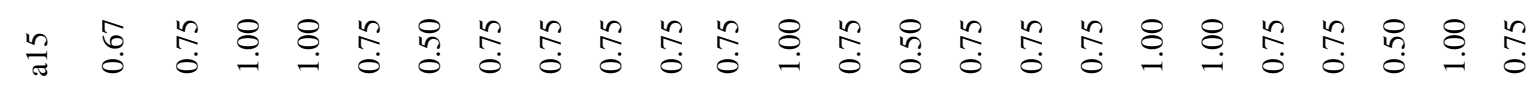

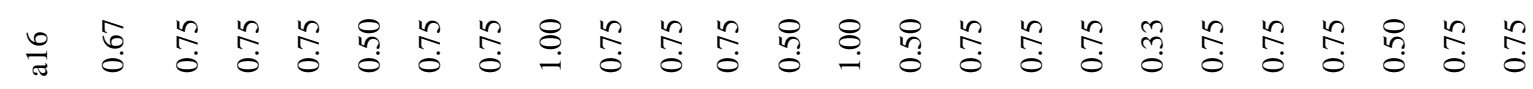

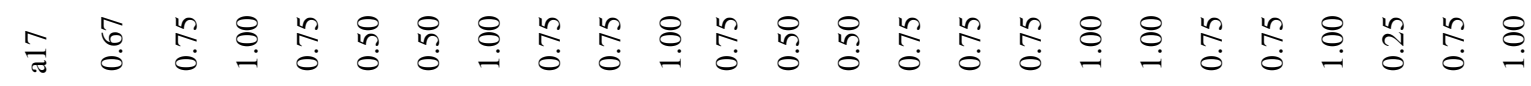

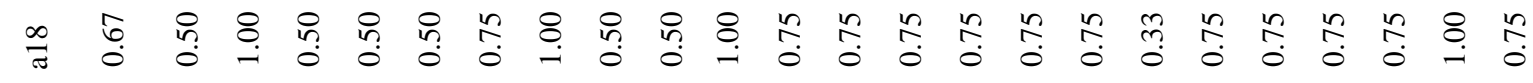

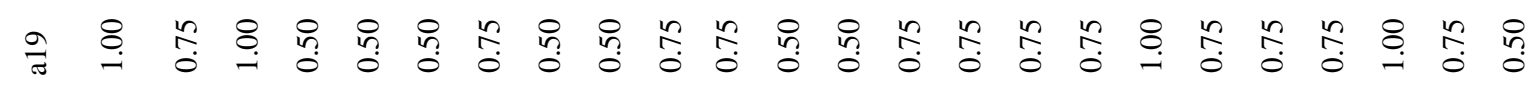

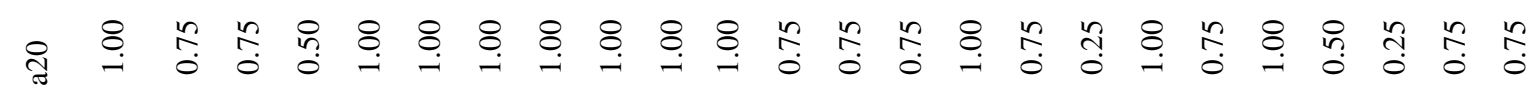

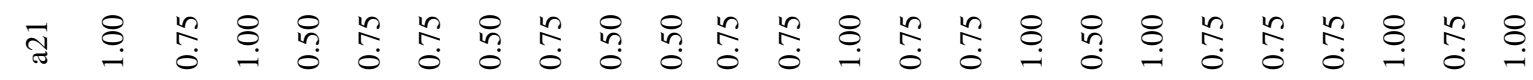

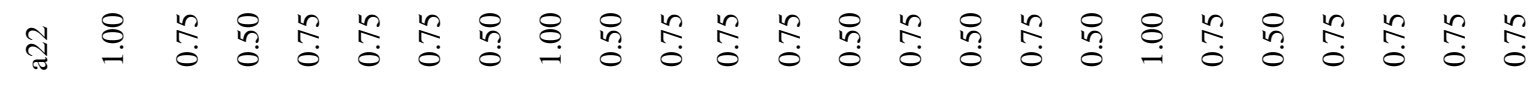

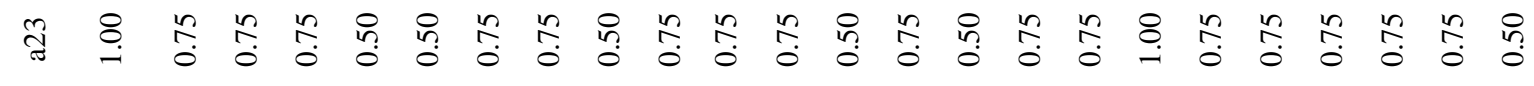

Semua data pada table 4 selanjutnya di normalisasi, nilai normalisasi diperoleh dari nilai setiap alternatif dibagi dengan nilai maksimal dari semua alternatif pada aspek yang sama.

E. Proses perangkingan 
Perangkingan dengan melakukan perkalian nilai normalisasi dari setiap alternatif dengan bobot setiap aspek pada tabel 1.,

$$
\text { total }=\text { nilainormalisasi } i_{A 1} x \text { bobot } c 1+\cdots+\text { nilainormalisas } i_{A 23} x \text { bobot } c 23
$$

sehingga dihasilkan tabel nilai total sebagai berikut

Tabel 6. Nilai total

\begin{tabular}{|c|c|c|c|}
\hline Alternatif & Total & Alternatif & Total \\
\hline a1 & 75.50 & a13 & 72.42 \\
\hline a2 & 72.00 & a14 & 74.08 \\
\hline a3 & 72.25 & a15 & 78.08 \\
\hline a4 & 76.75 & a16 & 71.75 \\
\hline a5 & 68.75 & a17 & 76.83 \\
\hline a6 & 77.67 & a18 & 71.75 \\
\hline a7 & 80.33 & a19 & 71.75 \\
\hline a8 & 78.75 & a20 & 79.00 \\
\hline a9 & 72.75 & a21 & 80.00 \\
\hline a10 & 74.08 & a22 & 70.00 \\
\hline a11 & 75.08 & a23 & 70.50 \\
\hline
\end{tabular}

Setelah semua nilai alternatif sudah melalui proses normalisasi, maka nilai normalisasi dikalikan dengan nilai bobot setiap alternatif. Nilai total dengan menjumlahkan hasil perkalian nilai normalisasi setiap alternatif dengan nilai bobot setiap aspek

Tabel 7. Hasil Perangkingan

\begin{tabular}{llrlllll}
\hline Rangking & Alternatif & Total & & & Rangking & Alternatif & Total \\
\cline { 1 - 4 } \cline { 5 - 7 } 2 & a7 & 80.33 & & 13 & a14 & 74.08 \\
2 & a21 & 80 & & 14 & a 9 & 72.75 \\
3 & a20 & 79 & & 15 & a13 & 72.42 \\
4 & a8 & 78.75 & & 16 & a3 & 72.25 \\
5 & a15 & 78.08 & & 17 & a2 & 72 \\
6 & a12 & 77.75 & & 18 & a16 & 71.75 \\
7 & a6 & 77.67 & & 19 & a18 & 71.75 \\
8 & a17 & 76.83 & & 20 & a19 & 71.75 \\
9 & a4 & 76.75 & & 21 & a23 & 70.5 \\
10 & a1 & 75.5 & & 22 & a22 & 70 \\
11 & a11 & 75.08 & & 23 & a5 & 68.75 \\
12 & a10 & 74.08 & & & &
\end{tabular}

Nilai tertinggi diperoleh alternatif a7 dengan nilai total 80.33 dari perolehan nilai aspek $=4$ sebanyak 6 buah aspek (c3,c10,c16,c19,c24), hasil ini ternyata melebihi hasil yang diperoleh alternatif a20 dengan nilai total 79 dengan nilai aspek $=4$ sebanyak 9 buah aspek $(\mathrm{c} 5, \mathrm{c} 6, \mathrm{c} 7, \mathrm{c} 8, \mathrm{c} 9, \mathrm{c} 10, \mathrm{c} 11, \mathrm{c} 15, \mathrm{c} 20)$. Hal ini disebabkan nilai aspek $=4$ yang diperoleh alternatif a7 terdapat pada jenis aspek yang bobotnya paling tinggi dibanding yang diperoleh alternatif a20

\section{Kesimpulan}

TRANSFORMATIKA Vol. 17, No. 1, July 2019: $26-33$ 
Dari hasil uji diatas disimpulkan alternatif a7 menempati rangking tertinggi dengan nilai 80.33 melalui perolehan nilai maksimal 4 sebanyak 6 aspek (c3,c10,c16,c19,c24), nilai 3 sebanyak 15 aspek (c2,c4,c5,c7,c8,c9,c11,c12,c14,c15,c17,c18,c20,c21,c22,c23) dan nilai 2 pada 3 aspek (c1,c6,c13).

Bobot nilai dari setiap aspek sangat berpengaruh terhadap nilai akhir yang diperoleh setiap alternatif, semakin banyak nilai maksimal yang menempati aspek dengan bobot tertinggi maka alternatif akan berpotensi menempati rangking lebih atas.

\section{Daftar Pustaka}

[ [1]Peraturan Kapolri, Peraturan Kepala Kepolisian Republik Indonesia No. 4 Tahun 2007, tentang Sistem Manajemen Pengamanan Organisasi, Perusahan dan/ atau Instansi / Lembaga Pemerintahan, 2007.

[ [2]Adityo Permana Wibowo and Sri Hartati, "Sistem Klasifikasi Kinerja Satpam Menggunakan Metode Naive Bayes Classifier," Jurnal Inovtek Polbeng, vol. 1, pp. 192 - 201, 2016.

] [3]Elik Yuli Arianto and Fernando B. Siahaan, "Aanalisa Penilaian Kinerja Karyawan Dengan Metode Fuzzy Simple Additive Weighting Pada PT. Unilever Indonesia Tbk," Jurnal Teknik Komputer, pp. 194 - 204, 2018.

[ [4]Nufus Hayatun, Dihardjo Soepeno Wudjud, and Agus Solikin, "Penilaian Kinerja Karyawan Dengan Menggunakan Metode Fuzzy Simple Additive Weighted (FSAW)," Journal of Mathematics Education, Science and Technology, pp. 125 136, 2016.

[ [5]Ulfah Septiani and Tristiyanto, "Sistem Informasi Penilaian Kinerja Karyawan Berbasis Metode Simple Additive Weighting (SAW) dan 360 Derajat Pada PLTD/G Tarahan," Jurnal Komputasi, pp. 64 - 73, 2017.

[ [6]Ramadan A ZeinEldin and Bandar M. Abdullah, "Comparing Two Multi-Criteria Approaches to Investigate Their Ability in Measuring Efficiency," International Journal for Modern Trends in Science and Technology, pp. 52 - 56, 2017.

[ [7]Mehdi Hatami Manesh and Seyed Mahmood Zanjirchi, "Weighting indicators of employee performance evaluation," European Online Journal of Natural and Social Sciences 2013, pp. 875-880, 2013.

[ [8]Sekar Ayu Rizkandari and Ristu Saptono, "Pemanfaatan Metode Simple Additive Weighting (SAW) Dalam Penentuan Mahasiswa Berprestasi Tingkat Universitas Sebelas Maret Surakarta," 2014.

[9]2011 SK Rektor, Keputusan Rektor Universitas Negeri Malang, Nomor 32/KEP/H32/KEP/OT/2011, 2011. 